\title{
Peduli Bencana Banjir dan Sosialisasi Pencegahan Penularan Covid 19 kepada Masyarakat Terdampak Banjir di Desa Antasan Sutun Kecamatan Martapura Barat Kabupaten Banjar
}

\author{
Jamilah*, Mochamad Priono, Jumriadi, St. Aisyah, Mukhyar Amani \\ Universitas Terbuka Banjarmasin, Indonesia \\ *Coresponding Author : jamilah-bjm@ecampus.ut.ac.id \\ Dikirim: 23-07-2021 ; Direvisi: 01-08-2021 ; Diterima: 05-08-2021
}

\begin{abstract}
Abstrak: Banjir yang melanda Kalimantan Selatan di bulan Januari menyebabkan banyaknya korban jiwa dan rusaknya sarana prasarana terutama di Kabupaten Banjar yang rusak parah. Penanggulangan banjir dilaksanakan secara bertahap dari pencegahan sebelum banjir, penanganan saat banjir, dan pemulihan saat banjit. Tahapan tersebut berada dalam suatu siklus kegiatan penanggulangan banjir yang berkesinambungan. Solusi yang dapat dilakukan adalah tidak hanya mengharapkan dari pemerintah saja, tetapi partisipasi dari masyarakat dan stakeholder yang harus saling bersinergi untuk mencegah datangnya banjir seperti tahun ini. Sasaran dalam kegiatan ini yaitu warga di Martapura Kabupaten Banjar dengan memberikan paket sembako dan penyuluhan pencegahan covid-19 yang sekarang masih melanda Indonesia.
\end{abstract}

Kata Kunci: peduli bencana banjir; pencegahan covid 19

\begin{abstract}
Floods that hit South Kalimantan in January caused many casualties and damaged infrastructure, especially in Banjar Regency, which was badly damaged. Flood management is carried out in stages from pre-flood prevention, flood management, and flood recovery. These stages are in a continuous cycle of flood prevention activities. The solution that can be done is not only expecting from the government, but also the participation of the community and stakeholders who must work together to prevent floods like this year. The targets in this activity are residents in Martapura, Banjar Regency by providing food packages and counseling on the prevention of COVID-19 which is still hitting Indonesia.
\end{abstract}

Keywords: care about flood disasters; Covid-19 prevention

\section{PENDAHULUAN}

\section{Deskripsi Wilayah}

Topografi wilayah Kabupaten Banjar berkisar antara 0-1.878 meter dari permukaan laut (DPL). Ketinggian ini merupakan salah satu faktor yang menentukan letak kegiatan penduduk sehingga ketinggian juga dipakai sebagai penentuan batas wilayah usaha dimana $35 \%$ berada di ketinggian 0-7 m dpl, 55,54\% terdapat pada ketinggian 50-300 $\mathrm{m}$ dpl dan sisanya yaitu sebanyak 9,45\% berada pada ketinggian lebih dari $300 \mathrm{~m}$ dpl. Rendahnya letak Kabupaten Banjar dari permukaan laut menyebabkan aliran air pada permukaan tanah menjadi kurang lancar. Akibatnya sebagian wilayah selalu tergenang $(29,93 \%)$ sebagian lagi $(0,58 \%)$ tergenang secara periodik. Sedangkan dilihat dari segi kemiringan lereng, Kabupaten Banjar cukup bervariatif. Hal tersebut dapat dilihat dari kondisi morfologi wilayah Kabupaten Banjar yang terdiri dataran yang landai, bergelombang, berbukit, sehingga ke bentuk morfologi pergunungan. 


\section{Latar Belakang}

Penanggulangan banjir dilakukan secara bertahap, dari pencegahan sebelum banjir (prevention), penanganan saat banjir (response/intervention), dan pemulihan setelah banjir (recovery). Tahapan tersebut berada dalam suatu siklus kegiatan penanggulangan banjir yang berkesinambungan. Kegiatan penanggulangan banjir mengikuti suatu siklus (life cycle), yang dimulai dari banjir, kemudian mengkajinya sebagai masukan untuk pencegahan (prevention) sebelum bencana banjir terjadi kembali. Pencegahan dilakukan secara menyeluruh, berupa kegiatan fisik seperti pembangunan pengendali banjir di wilayah sungai (in-stream) sampai wilayah dataran banjir (off-stream), dan kegiatan non-fisik seperti pengelolaan tata guna lahan sampai sistem peringatan dini bencana banjir.

Setelah pencegahan dilaksanakan, dirancang pula tindakan penanganan (response/intervention) pada saat bencana banjir terjadi. Tindakan penanganan bencana banjir, antara lain pemberitahuan dan penyebaran informasi tentang prakiraan banjir (flood forecasting information and dissemination), tanggap darurat, bantuan peralatan perlengkapan logistik penanganan banjir (flood emergency response and assistance), dan perlawanan terhadap banjir (flood fighting). Pemulihan setelah banjir dilakukan sesegera mungkin, untuk mempercepat perbaikan agar kondisi umum berjalan normal. Tindakan pemulihan, dilaksanakan mulai dari bantuan pemenuhan kebutuhan hidup sehari-hari, perbaikan sarana-prasarana (aftermath assistance and relief), rehabilitasi dan adaptasi kondisi fisik dan non-fisik (flood adaptation and rehabilitation), penilaian kerugian materi dan non-materi, asuransi bencana banjir (flood damage assessment and insurance), dan pengkajian cepat penyebab banjir untuk masukan dalam tindakan pencegahan (flood quick reconnaissance study).

\section{METODE PELAKSANAAN KEGIATAN}

\section{Khalayak Sasaran}

Sasaran kegiatan Pengabdian Kepada Masyarakat ini adalah Warga Masyarakat terdampak banjir di Desa Antasan Sutun Kecamatan Martapura Barat Kabupaten Banjar.

\section{Metode Kegiatan}

Metode kegiatan yang digunakan adalah dengan langsung memberikan bantuan berupa paket sembako dan penyuluhan pencegahan Covid 19 kepada masyaraakt terdampak banjir di Desa Antasan Sutun Kecamatan Martapura Barat Kabupaten Banjar.

\section{IMPLEMENTASI KEGIATAN DAN PEMBAHASAN}

Foto Dokumentasi Pelaksanaan Pengabdian kepada Masyarakat Dosen

@ 2021 Bima Abdi (https://bimaberilmu.com/jurnal/index.php/bp-jpm) 


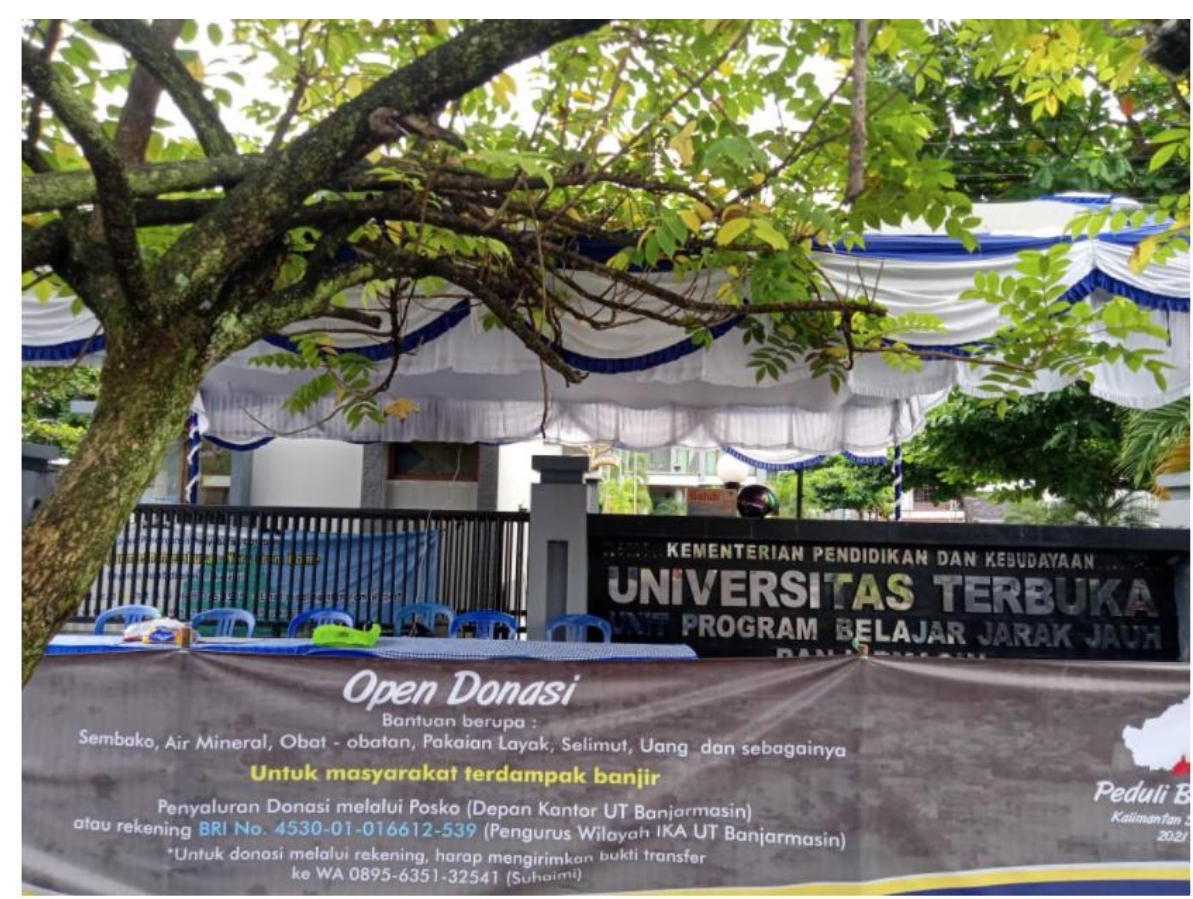

Gambar 1. Posko Penerimaan Bantuan Bencana banjir UT Banjarmasin

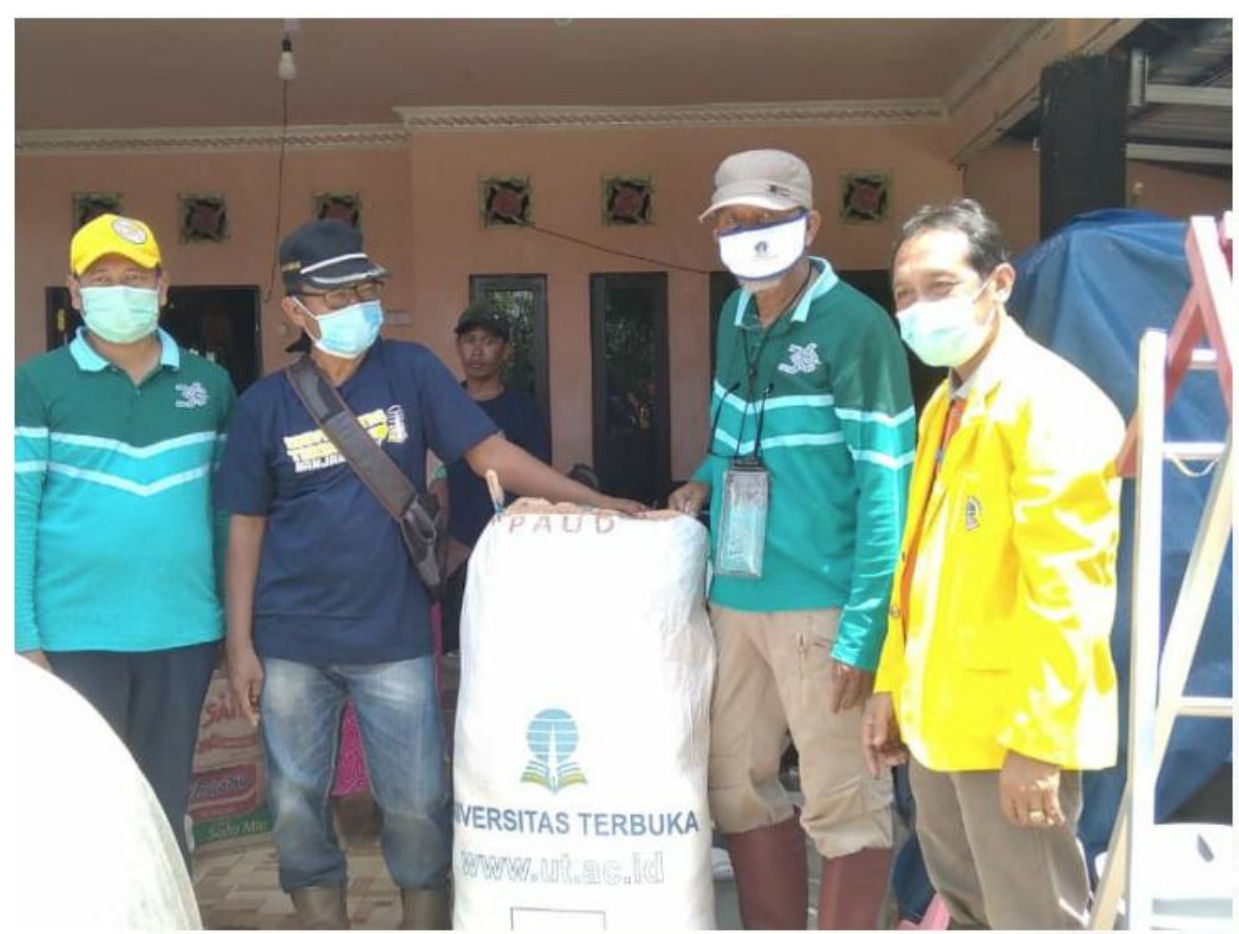

Gambar 2. Persiapan menuju lokasi dampak bencana banjir 


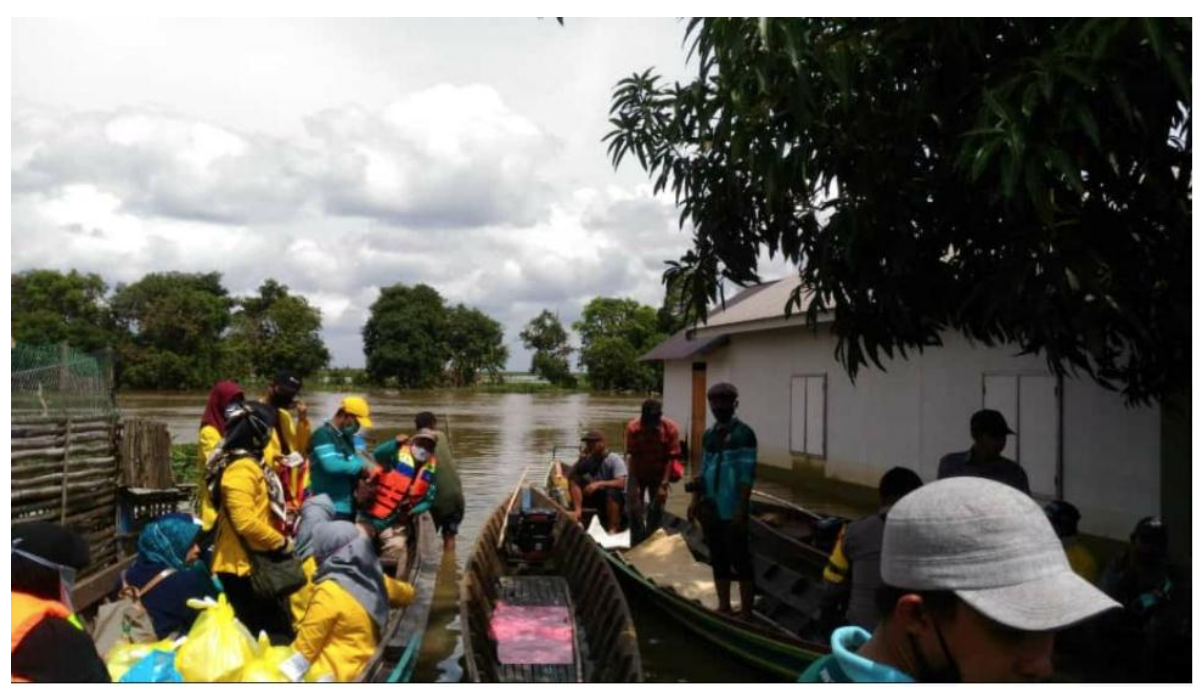

Gambar 3. Transportasi menuju ke lokasi terdampak bencana banjir

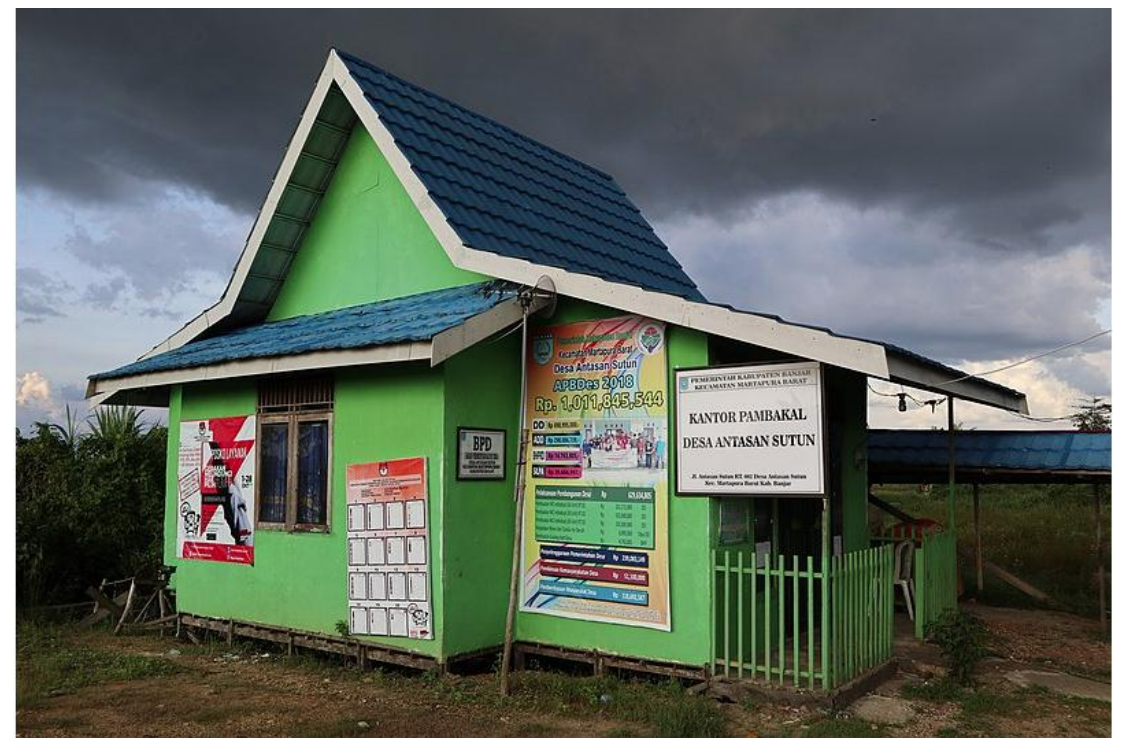

Gambar 4. Kantor Pembakal Desa Antasan Sutun Kecamatan Martapura Barat

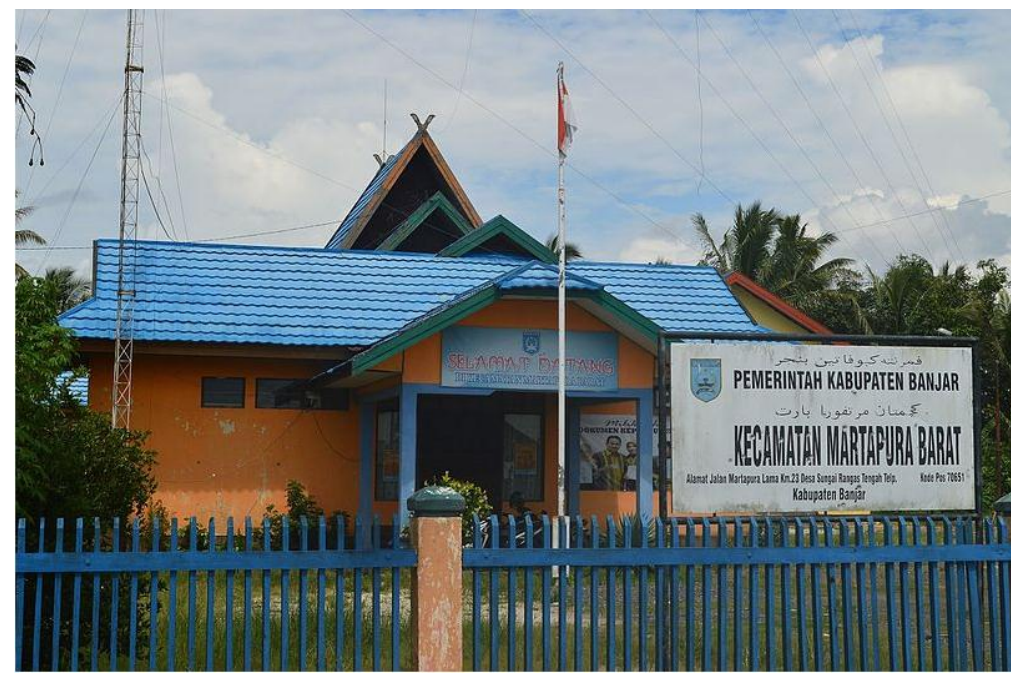

Gambar 5. Kantor Kecamatan Martapura Barat

@2021 Bima Abdi (https://bimaberilmu.com/jurnal/index.php/bp-jpm)

Ciptaan disebarluaskan di bawah Lisensi Creative Commons Atribusi 4.0 Internasional (c) (i) 


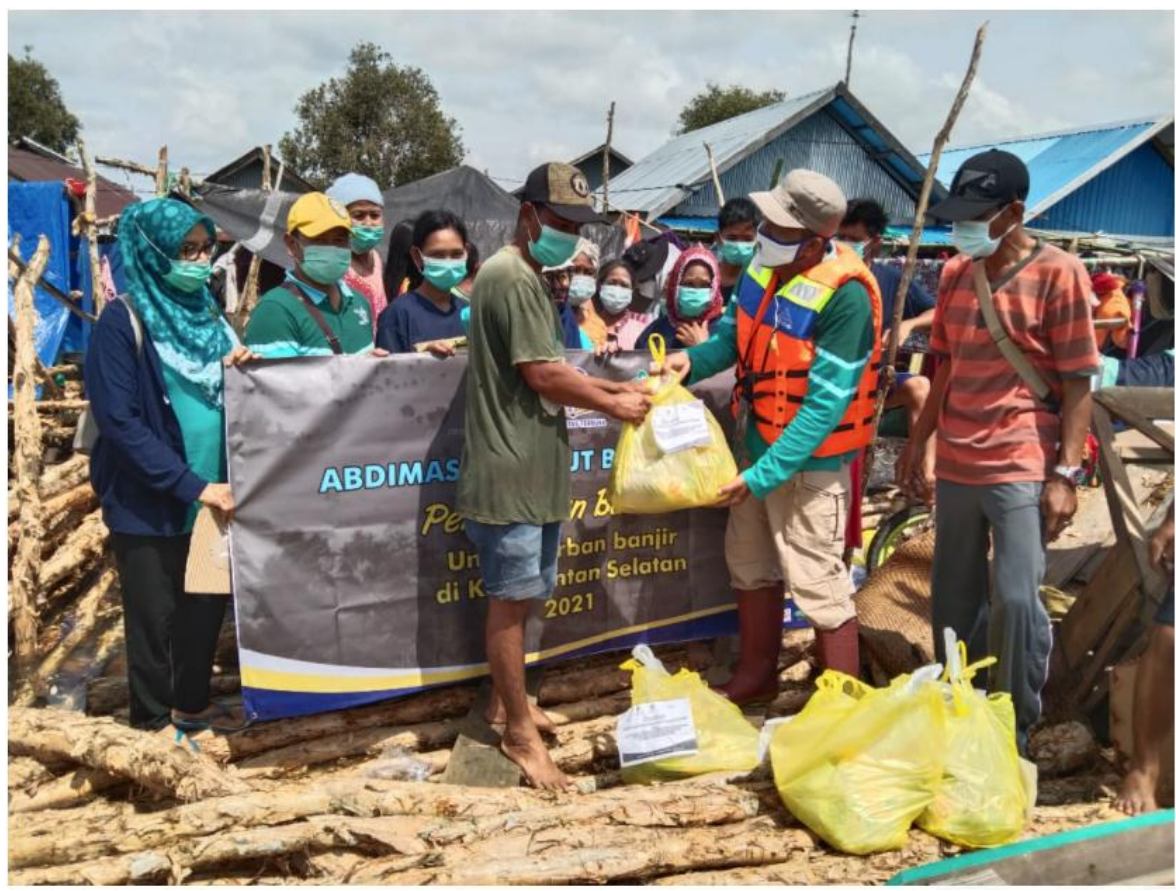

Gambar 6. Penyerahan Bantuan kepada Korban Bencana Banjir oleh TIM Relawan UT Banjarmasin

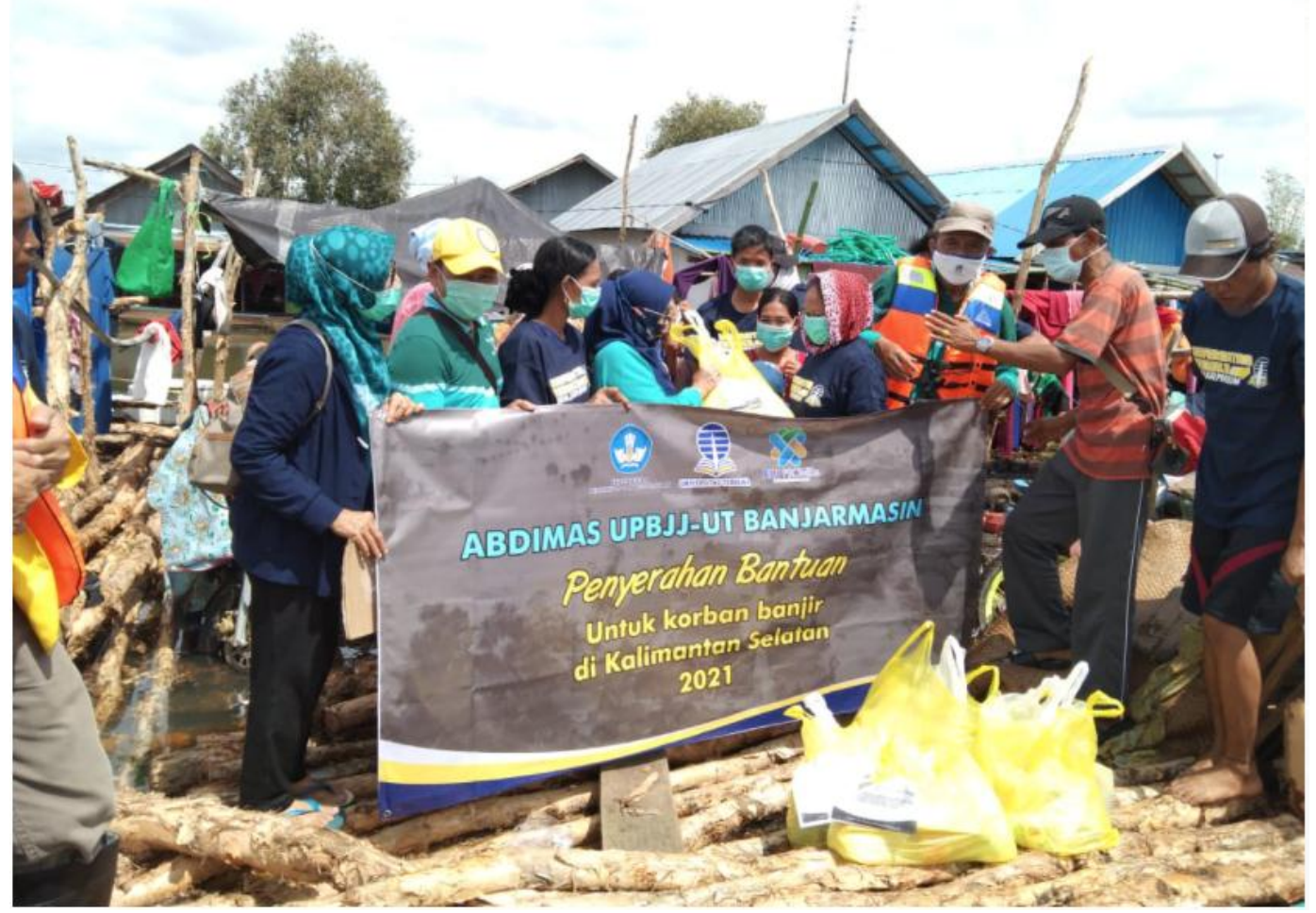

Gambar 7. Penyerahan Bantuan kepada Korban Bencana Banjir oleh TIM Relawan UT Banjarmasin

Partisipasi masyarakat merupakan proses teknis untuk memberi kesempatan dan wewenang lebih luas kepada masyarakat, agar masyarakat mampu memecahkan berbagai persoalan bersama-sama. Pembagian kewenangan ini dilakukan berdasarkan tingkat keikutsertaan (level of involvement) masyarakat dalam kegiatan 
tersebut. Partisipasi masyarakat bertujuan untuk mencari solusi permasalahan lebih baik dalam suatu komunitas, dengan membuka lebih banyak kesempatan bagi masyarakat untuk memberi kontribusi sehingga implementasi kegiatan berjalan lebih efektif, efisien, dan berkelanjutan. Stakeholder penanggulangan banjir secara umum dikelompokkan menjadi tiga, yaitu: (1) beneficiaries, masyarakat yang mendapat manfaat/dampak secara langsung maupun tidak langsung; (2) intermediaries, kelompok masyarakat atau perseorangan yang dapat memberi pertimbangan atau fasilitasi dalam penanggulangan banjir, antara lain: konsultan, pakar, LSM, dan profesional di bidang SDA.; (3) decision/ policy makers, lembaga/institusi yang berwenang membuat keputusan dan landasan hukum, seperti lembaga pemerintahan dan dewan sumberdaya air.

Sejalan dengan tuntutan masyarakat akan keterbukaan dalam program-program pemerintah, maka akuntabilitas pemerintah dapat dinilai dari sejauh mana partisipasi masyarakat dan pihak terkait (stakeholder) dalam program pembangunan. Partisipasi masyarakat, mulai dari tahap kegiatan pembuatan konsep, konstruksi, operasional pemeliharaan, serta evaluasi dan pengawasan. Penentuan dan pemilahan stakeholder dilakukan dengan metode Stakeholders Analysis yang terdiri dari empat tahap yaitu: (1) identifikasi stakeholder; (2) penilaian ketertarikan stakeholder terhadap kegiatan penanggulangan banjir; (3) penilaian tingkat pengaruh dan kepentingan setiap stakeholder; (4) perumusan rencana strategi partisipasi stakeholder dalam penanggulangan banjir pada setiap fase kegiatan. Semua proses dilakukan dengan mempromosikan kegiatan pembelajaran dan peningkatan potensi masyarakat, agar secara aktif berpartisipasi, serta menyediakan kesempatan untuk ikut ambil bagian, dan memiliki kewenangan dalam proses pengambilan keputusan dan alokasi sumber daya dalam kegiatan penanggulangan banjir. Tingkat partisipasi masyarakat dalam kegiatan penanggulangan banjir terdiri dari tujuh tingkat yang didasarkan pada mekanisme interaksinya, yaitu: (1) penolakan (resistancelopposition); (2) pertukaran informasi (information-sharing); (3) konsultasi (consultation with no commitment); (4) konsensus dan pengambilan kesepakatan bersama (concensus building and agreement); (5) kolaborasi (collaboration); (6) pemberdayaan dengan pembagian risiko (empowerment-risk sharing); (7) pemberdayaan dan kemitraan (empowerment and partnership).

Berawal dari kasus banjir, selain mengambil langkah penanggulangan dan tindakan terhadap masyarakat yang terkena banjir, pemerintah perlu melakukan review kasus untuk mengidentifikasikan penyebab, penentuan daerah banjir, jumlah kerugian, dan korban. Berdasarkan dua kegiatan tersebut, pemerintah membuat rencana penanggulangan bencana banjir jangka panjang dan rencana manajemen darurat banjir untuk persiapan menghadapi banjir, yang meliputi: (1) pemetaan daerah banjir; (2) stockpiling material; (3) identifikasi lokasi dan penggunaan perlengkapan flood-fighting; (4) pemeriksaan fasilitas pengendalian banjir; dan (5) persiapan penampungan pengungsi korban banjir. Hal ini dapat digunakan untuk menghadapi banjir berikutnya serta guna mengurangi jumlah korban dan kerugian.

\section{DAFTAR PUSTAKA}

Arsyad, (2010). Konservasi Tanah dan Air. Penerbit IPB. Bandung. 
Asdak, (2004). Hidrologi dan Pengelolaan Daerah Aliran Sungai. UGM Press: Yogyakarta.

Irianto, (2006). Pengelolaan Sumber Daya Lahan dan Air, Agro Inovasi:Jakarta.

Jaji Abdurrosyid dan Kirno. (2002). Banjir Bandang, Penyebab dan Solusinya di Situbondo Jawa Timur. Jurnal Teknik Gelagar, Fakultas Teknik Universitas Muhammadiyah Surakarta, Vol.13 No.03 Desember 2002, Surakarta.

Kodoatie, Robert J. dan Sugiyanto. (2002). Banjir, Beberapa penyebab dan metode pengendaliannya dalam perspektif Lingkungan, Pustaka Pelajar: Yogyakarta.

Luthfi. (2007). Metode Inventaris Sumber Daya Lahan, Andi OffSet: Yogyakarta. Mulyanto, (2007). Sungai, Fungsi dan Sifat-Sifatnya. Graha Ilmu: Yogyakarta.

Suripin. (2001). Pelestarian Sumber Daya Tanah dan Air. Penerbit Andi Offset: Yogyakarta.

Seta, AK. (1991). Konservasi Sumberdaya Tanah dan Air. Kalam Mulia:Jakarta. 